\title{
Study on the Marketing Strategy of Vipshop Sale
}

\author{
Suqing Gao \\ Wuhan University of Technology \\ Wuhan, China \\ 632504801@qq.com
}

\begin{abstract}
In order to analyze the marketing condition of special selling websites, this paper sets Vipshop Company as the research object, locating its market development status and environment, using PEST model, five forces model and other analysis methods to study the marketing strategy of Vipshop from the aspects of product, price, place and promotion. Finally, a detailed marketing strategy improvement scheme is proposed according to its market characteristics. The results of the study will have strong credibility and feasibility and will indicate the development direction for the marketing strategy of Vipshop.
\end{abstract}

Keywords-time limited sale; characteristics of market; marketing strategy

\section{INTRODUCTION}

According to the 37th "Statistical Report on Internet Development in China" released by the China Internet Network Information Center, as of the end of 2015, the number of Internet users in China was as high as 688 million. In other words, more than half of Chinese people have access to the Internet. With the continuous expansion of the number of Internet users, the growth rate of new Internet users surged by 1.1 percentage points from 2014, reaching 6.1\%. The increase in the number of Internet users is also affecting the development of the e-commerce industry. More and more consumers are shopping online, and the online consumer market has maintained a relatively fast growth rate. By the end of 2015, the number of online shoppers was $14.3 \%$ higher than that of 2014, reaching 413 million. Of which, the percentage of mobile shopping usage increased from $42.4 \%$ in 2014 to $54.8 \%$, and mobile phone online shopping reached 340 million with a growth rate of $43.9 \%$. In summary, with the rapid development of e-commerce, online shopping has gradually deepened the lives of ordinary consumers[1]. A variety of Internet marketing tools not only continue to attract consumers, but also make the shopping mentality of consumers have changed, Consumers' loyalty to a single website has been declining and the cost of acquiring users has also risen. Brand limited-time sales business as a offline marketing model is copied to the online market, and rapidly developed into one of the mainstream electricity supplier, creating a higher market performance and consumer repeat purchase rate. In this context, this paper takes Vipshop as an example, because the company is a special selling platform for domestic development, which has certain research significance and value[2]. In view of its special market development status and environment, the paper analyzes marketing strategy and proposes a detailed marketing strategy improvement plan according to the characteristics of consumers.

\section{MARKET POSITIONING AND MARKET CHARACTERISTICS}

Vipshop is aimed at "a dedicated website," which advocates refined and elegant life style. It pioneered the sale of the business model in the country. Coupled with the "zero inventory" mode of logistics management and seamless docking with e-commerce, it takes root in the field of ecommerce within a short period of time.

\section{A. Market positioning}

In the online shopping market, consumers are less influenced by geographical and political factors, so this article subdivides the online shopping market according to consumer behavior and psychology[3]. The main criteria are as follows: the age of online shopping consumers, the frequency of consumer shopping, consumer price sensitivity and consumer enthusiasm for the brand and consumer pursuit of product quality. According to the online shopping market segmentation analysis, it is easy to find Vipshop take young people who often shopping, sensitivity to commodity prices, higher keen brand pursuit and pay attention to product quality as the main target market of consumer groups, so take the brand discount + ensure quality goods market positioning[4].

\section{B. Market characteristics}

According to the analysis of the target market of Vipshop and the theory of consumer perceived value, it is concluded that the target market of Vipshop mainly has the following characteristics. First of all, due to the online shopping crowd mostly young people, relatively fast pace of life, so focus on the search speed and the clarity of the site page. Second, consumers pay more attention to product and price when spending. Third, keen on the pursuit of the brand, consumers think that the brand can represent their own quality of life, so when shopping more inclined to choose brand goods to highlight their own identity and status. Fourth, consumers have a certain sense of innovation, pay more attention to individual needs, and pay more attention to psychological recognition in the purchase decision-making, the pursuit of individuality has become the mainstream of consumption. Finally, love to share and be shared, consumers are more like to see others share in shopping and keen to share their shopping experience to others. The essence of network marketing is that the merchants and consumers exchange information to meet their own needs[5]. Therefore, in view of the new consumption characteristics arising from the online shopping environment, Vipshop should comply with the changes and development of consumer 
behavior, meet the new demands of consumers, and formulate corresponding marketing strategies[6].

\section{MARKET ENVIRONMENT AND COMPETITIVENESS ANALYSIS}

\section{A. Macro environment analysis}

This paper uses the PEST analysis method to conduct a macro environment analysis of the Vipshop. First of all, in the political environment, with the formulation of the "Internet +" plan, the further combination of the traditional offline industry and the online platform has brought new vitality to the Internet market. With the development of logistics and network technology, the network coverage rate continues to increase. Access to the Internet in rural areas is no longer a problem. This has increased the consumer market for e-commerce platforms. At the same time, the Ministry of Commerce actively formulates laws and regulations, standardizes the order of the electricity supplier market and guides the orderly development. Secondly, with regard to the economic environment, the economy of China has maintained sound and rapid economic growth in recent years. The per capita income of the country has risen gradually, the quality of life has been continuously improved, and the disposable income has been gradually increasing. Thirdly, in the technical environment, the development of mobile client APP makes the online shopping activities of consumers more convenient and faster. At the same time, the development of payment methods such as thirdparty payment and credit payment also raised the transaction rate of online shopping and the promotion rate of website platform. Finally, in terms of social and cultural environment, with the continuous expansion of Internet users and the gradual increase in Internet penetration, the target market for ecommerce platforms is also expanding. At the same time, consumers also have doubts and mistrust of whether the online product quality is qualified or not, which blocks the increase of online consumer volume.

Through the PEST analysis can be found that, in the face of the new macro environment, electric business platform need to be further carried out on the market positioning, real-time pay close attention to the new environment of change, according to the environment change constantly to meet consumers' real demand, stimulate the potential demand.

\section{B. Competitiveness analysis}

This paper mainly uses Porter five forces model to analysis the competitiveness of Vipshop, including competition with competitors in the industry, potential entrants threats, threats to alternatives, supplier bargaining power and consumer bargaining power

\section{1) Competition among competitors in the same industry}

The competition of existing enterprises is mainly reflected in price, product and after-sales service and other aspects. Vipshop's competitive pressures come first and foremost from large-scale e-commerce businesses that already have a stable foundation for growth, which are superior to Vipshop in terms of the breadth of consumer groups, price gradient and aftersales services. The second is that as with Vipshop, it's a website that USES brand discount competition. The last is from a number of websites that specialize in products of a certain type. They are more professional and focused on the sales of products and have more competitive advantages than Vipshop in the field of franchising.

\section{2) Potential entrants threaten}

Potential entrants are competitors that pose a potential threat even though they are not currently a threat to companies. For the Vipshop, the potential entrants in the market mainly refer to brand owners. Their own business development has been relatively complete, with some economies of scale and a strong brand influence.

\section{3) Consumer bargaining power}

The consumer bargaining power is mainly composed of price sensitivity and relative bargaining power. Vipshop uses a limited-time and low-priced operation mode to provide customers with the right products at the maximum discount. Coupled with its genuine guarantee and after-sales service to consumers to reduce consumer risk. This in a sense reduces the bargaining power of consumers.

\section{4) Supplier bargaining power}

The bargaining power of suppliers mainly refers to the ability of suppliers to raise the price of input elements and reduce the quality of the value of the unit products. For Vipshop, the cooperation method is relatively flexible and the cooperation process is simple, which saves unnecessary middle fees. At the same time, Vipshop has strong advantages in helping suppliers to reduce inventory and brand promotion. Suppliers' bargaining space is narrowing.

\section{5)Threats to alternatives}

When different enterprises or industries produce the same or similar products, respectively, their products are substitutes, and there is a certain competition behavior between alternatives, this competition also affects the development of the enterprise. For Vipshop, the alternatives are the brick-and-mortar stores of various brands and some of the off-line brand discount stores.

\section{AnAlysis Of Existing Marketing Strategies}

\section{A. Product}

In terms of product brand strategy, Vipshop's product strategy can be mainly summarized in the following four aspects: focus on brand effect, genuine guarantee, product range and focus on fashion sense. First of all, on the brand effect, Vipshop cleverly avoided some high-end luxury brands but chose some first-tier and second-tier brands to meet the consumers' desire to pursue the brand and meet the reasonable expectation of the brand price. Secondly, Vipshop provides products to ensure the authenticity of products, which enables consumers to purchase products without excessive consideration of product quality issues, Benefits are guaranteed and shopping satisfaction increases. Thirdly, the product covers a wide range and has a complete variety. Products from clothing, shoes, bags, household appliances, cosmetics to household goods, etc., It can meet the different needs of consumers at the same time, increase the retention period of consumers on the platform and increase the number of shopping products. Finally, Vipshop offers products that focus 
on fashion. Whether it's a clothing brand or a home product, Vipshop's products are all about fashion.

At the same time, the existing product strategy also has some problems. First, the lack of unique products, Vipshop at this stage most of the products are available with the mall or other e-commerce platform with the same paragraph, and the style of a single product, and other e-commerce platform there is no big gap, which undoubtedly reduced Own competitive advantage. Thirdly, there is a lack of interactivity in the platform of the website. Consumers can only see the information of the products when they purchase the products and can't see the evaluation of other consumers who have purchased or used the goods, which makes it impossible for consumers to understand the products objectively. At the same time, although Vipshop has after-sales service for goods, it is simply a brief introduction and lacks of artificial online services. There is a deficiency in providing satisfactory services to customers. Finally, the "fake" news frequently appears which undoubtedly increases consumers' distrust of consumers.

\section{B. Price}

The price strategy of Vipshop can be analyzed mainly from two aspects. First, on the supplier side, Vipshop adopts the "franchise minimum discount" strategy, which gives the supplier some preferential measures and conditions to get a minimum discount from the supplier. It attracts suppliers conditions mainly Vipshop "zero inventory" model, restricted time is short, inventory goods will not stay in the warehouse for a long time, it greatly shortens the settlement period with suppliers. But in the general store, settlement period is generally in 3 months or so. Second, for consumers, Vipshop is a "limited-time minimum discount". For general consumer purchase decisions, price is a relatively sensitive determinant, In Vipshop, not only can you buy the discounted products, but the brand is relatively high and has a quality guarantee, which greatly increases the purchasing power of customers. Vipshop provides consumers with limited time buying, not only in the limited time of product delivery, but also in the limited decision-making time. When consumers put their products in the shopping cart, they only have 15 minutes to buy the product. If they overtime, the product automatically removes the shopping cart. Such limited-time design reduces consumers' thinking time, stimulates consumers to complete consumption in a short period of time, and increases order completion. At the same time, the limited-time sale of the brand will attract consumers' attention to the platform.

\section{Place}

In terms of place management, Vipshop adopts centralized delivery of regional logistics center. It divided the country into four regions in North China, East China, Central China and Southwest China, and classified according to the address of the consumer, at the same time the regional sales brand and interface are different, the same brand will stagger the sales in different regions, not in the same area sales for a long time. At the same time, setting up regional logistics centers in major regions will not only reduce the pick-up and return time of consumers but also reduce the pressure on logistics and inventory, meanwhile, reduce the cycle of sending and receiving goods and increase the success rate of transactions. Such place management can shorten the time of storage of the product, improve the liquidity of the commodity greatly and effectively avoid the impact of the traditional channel of the supplier.

\section{Promotion}

The Vipshop promotion strategy is very obvious, namely "brand discount and time limit buying". When the combination of brand and discount, consumers greatly enhance the desire to buy, coupled with the limited time to buy an increase of consumer sense of urgency, so that the volume of products greatly improved. In addition to its own characteristics, Vipshop will also be some promotional methods of promotion, such as membership points, holiday offers, advertising promotions, etc.

\section{RECOMMENDATIONS}

In the new era of Internet economy, Vipshop first opens the specialize in home sales business model, its brand discount, flash and authentic guarantee signatures in order to be familiar to most online consumer groups, also have a loyal customer. The development prospects are very broad. According to the existing marketing strategy analysis of Vipshop, this article proposes some corresponding marketing strategy improvement solutions for Vipshop. Mainly to the main products.

1) Pay attention to the uniqueness of the product and differentiate the network marketing. Consumer shopping is designed to meet the needs of the product, so it should take into account the specific characteristics of consumers and offer different products to different consumers when providing products. By analyzing the consumer behaviors of online shopping consumers at this stage, it can be found that consumers are mostly young people or groups that have strong receptivity to new things. These consumers have a certain sense of innovation, want to be different, and the pursuit of individual needs. Therefore, Vipshop will be in efforts to meet the individual needs of consumers, more innovative products, and efforts to differentiate the product marketing, so that their products can be clearly distinguished to other e-commerce platform products and get a strong competitive advantage.

2) Development of social and interactive direction. Different from the traditional shopping method, consumers are facing computer pages rather than salespeople in shopping malls when shopping online. This not only increases consumers' independent thinking time but also makes consumers unable to understand products more clearly Information, so the Vipshop should enhance the social and interactive aspects of development. The measures are mainly two aspects, the socialization between the client and the customer, and the interaction between the customer and the merchant. Vipshop should, therefore, to strengthen the construction of social and interactive aspects, to carry out the special Commodity Exchange platform to make consumers can communicate with each other for the product evaluation and understanding, and to set a special artificial online services, to 
answer consumer questions at any time, increase consumer trust of platform.

3) Do well in the image processing of network public relations. The development of information technology has made netizens more sensitive to news. In choosing online shopping platform, consumers are more likely to have better brand reputation, so a well-publicized image of the public is important to the online platform. In the news, the word "Vipshop fake" is often seen, which is very unfavorable for the development of enterprises. Vipshop will regularly post some favorable information and posts on major social platforms or news media to increase consumers' trust in the company. For malicious slander netizens, should take the necessary legal means. At the same time, Vipshop has strengthened communication with netizens and timely grasped the psychological dynamic and demand of consumers.

\section{CONCLUSION}

This paper analyzes Vipshop product, price, place and promotion marketing strategy from environmental analysis. The study found that Vipshop is competitive in the current market competitive environment, which mainly comes from peer competition, potential entrants, and threat of substitutes. In terms of marketing strategy, Vipshop has a strong competitive advantage in price, place and promotion, but it has a slight deficiency in product. This paper proposes to improve product marketing strategy from three aspects: unique product, interactive platform and public relations image.

\section{REFERENCES}

[1] Gernard P. Cachon. The Value of Fast Fashion: Quick Response, Enhanced Design, and Strategic Consumer Behaviour[J]. Management Science,2011,Vol57,pp777-796

[2] Ning Mao,A brief analysis of Vipshop's network marketing status and development strategy group [J]. China commerce, 2014,Vol2,pp25-26.

[3] Hai Dong , Xiaoyan Quan, Xiaofei Qu. Customer value and its composition [J]. Journal of dalian university of technology (social science edition), 1999 ,Vol12,pp18-20

[4] Wei Zhang. A brief analysis on Vipshop network marketing strategy [J]. Modern economic information, 2013, Vol21,pp135-136

[5] Dan Zhi. Marketing strategy analysis of Vipshop [J]. China market, 2014, Vol5,pp32

[6] Wei Zhang.A brief analysis of Vipshop network marketing strategy [J]. Now we have the credit,2013, vol21,pp136-137 